\title{
EDITORIAL
}

\section{Household chemicals: good housekeeping or occupational hazard?}

\author{
P. Franklin
}

I $\mathrm{n}$ the Western world the role of air pollution in the initiation of respiratory disease in children is contentious [1]. There is good evidence that air pollution can trigger symptoms in susceptible children but its contribution to the pathogenesis of childhood respiratory disorders, such as asthma, remains unclear. There has been considerable interest in traffic-related pollutants and studies have investigated the prevalence of asthma and wheeze in children living near main roads [2-4]. While this remains an important area of research, there is also concern about exposure to air pollutants in the indoor environment. In developed countries, people spend most of their time indoors and in the case of many air pollutants, the indoor environment is the principal source of exposure.

For young children, the most important indoor environment is the home. On average, children spend $\sim 15 \mathrm{~h}$ a day indoors at home [5]. Infants average nearly $20 \mathrm{~h}$ per day indoors [6]. Indoor air pollutants, such as environmental tobacco smoke (ETS), nitrogen dioxide and formaldehyde, have been associated with adverse respiratory health outcomes in children [7]. In recent times, there have been concerns about domestic exposure to volatile organic compounds (VOCs) and other air toxics. Indoor air toxics, including VOCs, are emitted from a broad range of sources, including cleaning agents, furnishings, paints, cosmetics, aerosol sprays and pesticides. These products also contain chlorine, ammonia, surfactants, acids, bases and oxidants, and reactions between compounds can create highly irritative secondary pollutants [8]. The health effects of this chemical mix, at concentrations normally encountered in homes, is not yet known but there is some evidence that these exposures may be associated with wheeze [9-11] and allergy [12] in young children. The data, however, remain inconsistent [13].

Exposure to many environmental agents starts in the very early stages of life, during organogenesis, and the long-term health implications of these exposures is an area of increasing interest. Ambient air pollutants have been associated with adverse birth outcomes, such as low birth weight, prematurity, early foetal loss and sudden infant death [1], but the long-term consequences of early life exposures for respiratory health are

\section{STATEMENT OF INTEREST: None declared.}

CORRESPONDENCE: P. Franklin, Centre for Asthma, Allergy and Respiratory Research, 1st Floor, B Block, Sir Charles Gairdner Hospital, Nedlands, Western Australia 6009, Australia. Fax: 61 893464159. E-mail: peter.franklin@uwa.edu.au not yet known [14]. Apart from ETS, there are few data on early life exposures to indoor air pollutants.

In the current issue of the European Respiratory Journal, HENDERSON et al. [15] report on the association between mothers' use of household chemical products during pregnancy and persistent wheeze in school-aged children. HENDERSON et al. [15] found an association between maternal exposure to household chemicals during pregnancy and various wheeze phenotypes, including early and intermediateonset persistent wheeze, in the children when they reached 7 yrs of age. They also report a small adverse impact of these products on lung function in children, measured at age 8.5 yrs. The findings extend the authors' earlier data on the association between chemical use and persistent wheeze in infants [11]. Interestingly, in another prospective birth cohort study, the frequency of hairspray use in infants' bedrooms was associated with an increased risk of asthma when the children were 7 yrs old [16].

The study by Henderson et al. [15] is part of the Avon Longitudinal Study of Parents and Children (ALSPAC) study. The ALSPAC study is a large, population-based birth cohort of $>14,000$ children, which commenced in the early 1990s [17]. Data for the current analyses were available for $6,000-7,000$ children, depending on the outcome measure. Information regarding the respiratory health of the children was collected prospectively at regular intervals from birth to school age, allowing the investigators to assign the children to various wheeze categories without the potential misclassification that is associated with parental recall bias, which can occur in cross-sectional studies.

In assessing the findings of the study by HENDERSON et al. [15] there are three issues that need to be considered: exposure assessment, timing of exposure and biological plausibility. Exposure misclassification remains one of the main difficulties for environmental health studies. In the ALSPAC study, data were collected by questionnaire and exposure was calculated using a composite score based on the frequency of use of 11 common household chemicals. One of the strengths of the study was that investigators were able to collect environmental data during pregnancy, again reducing the potential for recall bias. Furthermore, the investigators measured VOCs in a subset of homes and reported increased concentrations with increased use of some products, specifically air fresheners and aerosols [18]. The validation of the assessment tool is laudable. However, exposure assessment is an evolving science and future studies need to consider methods to improve the 
exposure metric. One area of exposure assessment that has seen recent development is the use of biomarkers. It is now possible to measure very low concentrations of environmental chemicals or chemical by-products in human tissue [19]. Biomarkers of both exposure and effect are increasingly being used for environmental health research involving air pollutants $[20,21]$ and may provide more information about total exposure to these compounds. However, although biomonitoring offers exciting opportunities, there is still a limited understanding of the relationship between environmental concentrations and biomarkers, particularly for low-level exposures that occur in homes, as well as between biomarkers and health outcomes.

There is a growing recognition of the importance of the prenatal period as a "window of exposure" for the development of childhood, and possibly adulthood, disease [22]. HENDERSON et al. [15] have investigated the effects of mothers' exposure to household chemicals during pregnancy, but they acknowledged the difficulty in determining whether the reported health effects could be attributed to pre- or postnatal exposure, or even both. They observed that chemical use in the home before and after birth was highly correlated, making it difficult to separate potential effects of exposure during these periods. This problem has been encountered for many environmental agents, most notably ETS. The importance of in utero ETS exposure on lung health in young children is now well established [23]. Studies demonstrating impaired lung function in very young infants of mothers who smoked during pregnancy were instrumental in understanding the impact of prenatal exposure on respiratory health [24]. Measuring health outcomes, such as lung function, in the early post-natal period may help generate understanding concerning whether prenatal exposures to indoor, or indeed outdoor, air pollutants can impact on the lung development and respiratory health of children.

The mechanism by which air pollutants may contribute to the onset of respiratory disease remains unknown. Possibilities include alterations in immune function, direct impacts on lung development and airway irritation/inflammation. There is some evidence that maternal exposure to indoor VOCs may influence the immune status of neonates [25]. However, in the study by HENDERSON et al. [15], significant effects of household chemicals on wheeze were only evident in nonatopic (as determined by skin-prick test) children, arguing against foetal immune modulation by these compounds. Furthermore, VOCs and cleaning agents are not considered to be strong respiratory sensitisers [26]. In the study by HENDERSON et al. [15], there was a small affect of chemical use on lung function in the children. There is some evidence of an association between blood levels of some VOCs and reduced lung function in adults [27], but again the data are limited. As yet, there are no data, animal or human, on the effect of household chemicals on foetal or neonatal lung development. HENDERSON et al. [15] tentatively speculate that the association between persistent wheeze and chemical exposure may be analogous to occupational irritantinduced asthma. There are some difficulties in making this comparison, especially in relation to exposure levels. Although VOC concentrations are generally higher indoors than outdoors, indoor domestic concentrations are usually low [28] and are unlikely to be on a par with occupational exposure levels.
However, understanding of threshold levels of these pollutants remains poor, particularly for young children.

The study by HENDERSON et al. [15] adds to the small body of published literature on the potential harmful effects of chemicals in the home on the respiratory health of children. Although the evidence is far from conclusive and a greater understanding of how putative causative agents may contribute to disease is required, there may be sufficient evidence to caution people about the indiscriminate use of household chemical products, particularly during pregnancy and around young children. The household chemical industry is large. For example, the market for cleaning products is worth $\sim$ US\$4 billion a year in the USA alone. Ironically, many of these products are used to improve hygiene and aesthetics in homes and this suggests an alternative hygiene hypothesis: that household hygiene products can directly and adversely affect the lungs of young children.

\section{REFERENCES}

1 Schwartz J. Air pollution and children's health. Pediatr 2004; 113: 1037-1043.

2 Brauer M, Hoek G, Smit HA, et al. Air pollution and development of asthma, allergy and infections in a birth cohort. Eur Respir J 2007; 29: 879-888.

3 Duhme H, Weiland SK, Keil U, et al. The association between self-reported symptoms of asthma and allergic rhinitis and self-reported traffic density on street of residence in adolescents. Epidemiol 1996; 7: 578-582.

4 Wjst M, Reitmeir P, Dold S, et al. Road traffic and adverse effects on respiratory health in children. BMJ 1993; 307: 596-600.

5 Wiley JA, Robinson JP, Cheng Y-T, et al. Study of Children's Activity Patterns. Sacremento, Californian Air Resources Board, 1991.

6 Farrow A, Taylor H, Golding J. Time spent in the home by different family members. Environmental Technology 1997; 18: 605-613.

7 National Institutes of Medicine. Clearing the Air: Asthma and Indoor Air Exposures. Washington, National Academy Press, 2000.

8 Nazaroff WW, Weschler CJ. Cleaning products and air fresheners: exposure to primary and secondary air pollutants. Atmos Environ 2004; 38: 2841-2865.

9 Diez U, Kroessner T, Rehwagen M, et al. Effects of indoor painting and smoking on airway symptoms in atopy risk children in the first year of life results of the LARS-study. Leipzig Allergy High-Risk Children Study. Int J Hyg Environ Health 2000; 203: 23-28.

10 Rumchev KB, Spickett JT, Bulsara MK, Phillips MR, Stick SM. Association of domestic exposure to volatile organic compounds with asthma in young children. Thorax 2004; 59: 746-751.

11 Sherriff A, Farrow A, Golding J, Henderson J. Frequent use of chemical household products is associated with persistent wheezing in pre-school age children. Thorax 2005; 60: 45-49.

12 Herbarth O, Fritz GJ, Rehwagen M, Richter M, Roder S, Schlink U. Association between indoor renovation activities 
and eczema in early childhood. Int J Hyg Environ Health 2006; 209: 241-247.

13 Venn AJ, Cooper M, Antoniak M, Laughlin C, Britton J, Lewis SA. Effects of volatile organic compounds, damp, and other environmental exposures in the home on wheezing illness in children. Thorax 2003; 58: 955-960.

14 Kajekar R. Environmental factors and developmental outcomes in the lung. Pharmacol Therapeut 2007; 114: 129-145.

15 Henderson J, Sherriff A, Farrow A, Ayres JG. Household chemicals, persistent wheezing and lung function: effect modification by atopy? Eur Respir J 2008; 31: 547-554.

16 Ponsonby AL, Couper D, Dwyer T, Carmichael A, Kemp A, Cochrane J. The relation between infant indoor environment and subsequent asthma. Epidemiol 2000; 11: 128-135.

17 Golding J, Pembrey M, Jones R. ALSPAC - the Avon Longitudinal Study of Parents and Children. I. Study methodology. Paediatr Perinat Epidemiol 2001; 15: 74-87.

18 Farrow A, Taylor H, Northstone K, Golding J. Symptoms of mothers and infants related to total volatile organic compounds in household products. Arch Environ Health 2003; 58: 633-641.

19 Paustenbach D, Galbraith D. Biomonitoring and biomarkers: exposure assessment will never be the same. Environ Health Perspect 2006; 114: 1143-1149.

20 Sexton K, Adgate JL, Fredrickson AL, Ryan AD, Needham LL, Ashley DL. Using biologic markers in blood to assess exposure to multiple environmental chemicals for inner-city children 3-6 years of age. Environ Health Perspect 2006; 114: 453-459.
21 Whyatt RM, Camann D, Perera FP, et al. Biomarkers in assessing residential insecticide exposures during pregnancy and effects on fetal growth. Toxicol Appl Pharmacol 2005; 206: 246-254.

22 Yeatts K, Sly P, Shore S, et al. A brief targeted review of susceptibility factors, environmental exposures, asthma incidence, and recommendations for future asthma incidence research. Environ Health Perspect 2006; 114: 634-640.

23 Stick S. The effects of in utero tobacco-toxin exposure on the respiratory system in children. Curr Opin Allergy Clin Immunol 2006; 6: 312-316.

24 Stock J, Dezateux C. The effect of parental smoking on lung function and development during infancy. Respirology 2003; 8: 266-285.

25 Lehmann I, Thoelke A, Rehwagen M, et al. The influence of maternal exposure to volatile organic compounds on the cytokine secretion profile of neonatal $\mathrm{T}$ cells. Environ Toxicol 2002; 17: 203-210.

26 Nielsen GD, Larsen ST, Olsen O, et al. Do indoor chemicals promote development of airway allergy? Indoor Air 2007; 17: 236-255.

27 Elliott L, Longnecker MP, Kissling GE, London SJ. Volatile organic compounds and pulmonary function in the Third National Health and Nutrition Examination Survey, 19881994. Environ Health Perspect 2006; 114: 1210-1214.

28 Raw GJ, Coward SK, Brown VM, Crump DR. Exposure to air pollutants in English homes. J Expo Anal Environ Epidemiol 2004; 14: Suppl. 1, S85-S94. 